\title{
Quantifying uncertainty in mining geomechanics design
}

\author{
MJ Dunn Evolution Mining Ltd, Australia
}

\begin{abstract}
Uncertainty in mining geomechanics and geotechnical engineering is a broad term that accounts for natural variability, lack of data, and lack of knowledge. Reducing uncertainty is a key component of the mining study process and in managing geomechanical/geotechnical risk. Understanding and reducing uncertainty is also a key activity in the design process to ensure that designs are robust and resilient.

A variety of methods are used in geomechanical design including empirical, analytical and numerical modelling. All design methods require inputs, and these are based on data from core logging, mapping, laboratory testing, field observations, and monitoring. This data then must be compiled and interpreted so that meaningful and reliable design inputs with a reliability that is commensurate with the level of design (scoping through to operational) can be derived. This includes the development of the geomechanical or geotechnical model. The uncertainty of the geotechnical model is often described in terms of confidence or reliability.
\end{abstract}

Currently, very little quantitative guidance exists in the literature on assessing the confidence level of geotechnical studies and design, although there have been attempts by various authors (Haile 2004; Haines et al. 2006; Read 2009; Dunn et al. 2011) to qualitatively describe what level of geotechnical data is required. Several authors have outlined methods that could be applied to assess the reliability of geotechnical data (Read 2013; Fillion \& Hadjigeorgiou 2013; Dunn 2015).

Data from a range of projects are reviewed and summarised and an attempt made to quantify the uncertainty for some data, and illustrate the impact this can have on designs and commonly used design acceptance criteria.

Keywords: uncertainty, risk, reliability

\section{Introduction}

In mining geomechanics it is generally accepted that designs should have a confidence level that is commensurate with the project's position within the project lifecycle. The project lifecycle covers the scoping, pre-feasibility, feasibility, final design, construction, and closure stages. A key component to defining the confidence level and reliability of the design is the confidence and reliability of the design input parameters. The design reliability has a direct link and influence on safety and economic risk.

In mining geomechanical engineering, the development of reliable input parameters can be challenging and often it is difficult to assess the level of reliability. This paper attempts to outline some of the issues associated with developing reliable design input parameters.

The terms geomechanical and geotechnical engineering are used interchangeably, and there is no one accepted definition (Vyazmensky 2017). For consistency, the term geomechanical is used in this paper unless it relates to a specific reference that uses the term geotechnical.

\section{Geomechanical design}

A variety of design methods are used for geomechanical mine design. These can broadly be classed as empirical, observational, analytical, and numerical methods, and these are discussed in previous papers by the author (Dunn 2014, 2015). Irrespective of what design method is used and whether the design approach is deterministic or probabilistic, the reliability of the design is largely influenced by the reliability of input parameters. 
The reliability of design inputs is a function of being able to reduce or minimise geomechanical uncertainty. Several authors (Peck 1969; Bieniawski 1992; Stacey 2004, 2008, 2009) have written significant papers on geomechanical design and all three authors outline the need for minimising uncertainty or considering unfavourable variations in design inputs. A review of the design principles described by these authors is provided by Dunn (2013) and will not be repeated in this paper.

\section{Geomechanical uncertainty}

The term 'uncertainty' is loosely applied in geomechanical engineering. McMahon (1985) outlined six types of uncertainty encountered in geomechanical engineering and these are broadly divided into natural uncertainty and uncertainty related to human nature. Baecher and Christian (2003) provide a similar division and distinguish between uncertainty related to natural variations in time and space (randomness) and uncertainty related to lack of understanding or knowledge. These are referred to as aleatory and epistemic uncertainty, respectively, by Kiureghian and Ditlevsen, as cited in Hadjigeorgiou and Harrison (2011). Brown (2007) concluded that there are two general types of uncertainty:

- Parameter uncertainty - what we know we don't know.

- Conceptual uncertainty - what we do not know we do not know.

Read (2009) states that the various types of uncertainty can be placed into three groups: geological uncertainty, parameter uncertainty and model uncertainty.

The terms 'confidence' and 'reliability' are often used when discussing geomechanical uncertainty and these terms are often used interchangeably when discussing geotechnical data and models, which can be confusing.

Confidence can be expressed as a level or an interval. A confidence level refers to the percentage of all possible samples that can be expected to include the true population parameter. Statisticians use a confidence level to describe uncertainty associated with the interval estimate.

A confidence interval is used to express the degree of uncertainty associated with a sample statistic. A confidence interval is an interval estimate combined with a probability statement. Confidence intervals are preferred to point estimates and to interval estimates, because only confidence intervals indicate the precision of the estimate and the uncertainty of the estimate.

Reliability is a statement of error or precision of an estimate. Data reliability is a state that exists when data is sufficiently complete and error-free to be convincing for its purpose and context. Data reliability should not be confused with design reliability, which has a different definition but ultimately data reliability will impact on design reliability.

\section{Geomechanical model}

The geomechanical or geotechnical model forms the basis of any design whether it be in an open pit or an underground design. Read (2009) defines the requirements for open pit slope design and these do not differ markedly for underground design, with the exception that stress is a more significant issue in underground mines and needs to be quantified (Table 1). Brown (2007) and Villaescusa (2014) describe some of the requirements for underground cave mining and sublevel open stoping respectively. The quality and reliability of a geotechnical model is largely dependent on the quantity and quality of the data collected for the purposes of developing the geotechnical model. 
Table 1 Overview of geotechnical model components

\begin{tabular}{ll}
\hline Component & Description \\
\hline Geological model & $\begin{array}{l}\text { The geological model generally consists of the lithology, alteration, } \\
\text { weathering, mineralised zones and the in situ stress state. The reliability } \\
\text { of boundaries between zones is a key issue. } \\
\text { Consists of the major structures (large faults, bedding and folds) and } \\
\text { minor structures or fabric (joints and minor faults). } \\
\text { The reliability of the location of major structures is a key issue as these } \\
\text { often play a significant role in controlling instability. }\end{array}$ \\
Hydrogeological & $\begin{array}{l}\text { The hydrogeological model consists of hydrogeological units, hydraulic } \\
\text { conductivities, flow regimes, phreatic surfaces and the pore pressure } \\
\text { distribution, and water quality distribution. }\end{array}$ \\
Rock mass model & $\begin{array}{l}\text { The rock mass model consists of the intact rock strength, defect shear } \\
\text { strength, rock mass strength and rock mass classification. These are used } \\
\text { to determine the input parameters for geotechnical analyses thus } \\
\text { understanding their variability and reliability is a key issue. } \\
\text { Geotechnical or geomechanical domains that exhibit similar rock mass } \\
\text { and structural characteristics. Geotechnical domains form the basis of } \\
\text { geotechnical design sectors or areas. }\end{array}$ \\
\hline
\end{tabular}

Steffen (1997), Haile (2004) and Haines et al. (2006) have all provided guidance on the geotechnical data requirements and qualitative descriptions of the geotechnical model. Read (2009) provides guidance on target confidence levels required for geotechnical models necessary for large open pit slope design for different project stages (Table 2). They consider conceptual (Level 1); pre-feasibility (Level 2); feasibility (Level 3); design and construction (Level 4); and operations (Level 5), as shown in Table 2. Descriptive guidelines for estimating the level of confidence in the data for each model component at each level of development are also provided. For consistency with the reporting of exploration results, mineral resources and ore reserves, the guidelines were purposely matched with the descriptive framework used by the 2004 Australian JORC code (Joint Ore Reserves Committee 2004). The JORC code was updated in 2012 (Joint Ore Reserves Committee 2012).

Cepuritis and Villaescusa (2012) outline the data and design reliability required for open stope span design, as well as what design methods should be applied for different project stages. The suggested reliabilities are similar to those proposed by Read (2009) and are as follows:

- Conceptual: $<50 \%$.

- Pre-feasibility: 50-60\%.

- Feasibility: $60-70 \%$.

- Initial construction: $70 \%$.

- Early to mid-life operations: $80 \%$.

- Mature operations: $85 \%$.

Cepuritis and Villaescusa (2012) also outline design reliabilities for each stage which are the same as the rock mass or geomechanical model reliabilities. The various guidelines mentioned above are useful, but are essentially qualitative in nature and are subjective, often requiring considerable engineering judgement in their application. 
Several authors (Read 2009; Cepuritis \& Villaescusa 2012) have attempted to allocate numerical values to the required confidence levels or reliability, however, no guidance is provided on how these should be calculated or estimated.

Table 2 Suggested target levels of data confidence by project stage (after Read 2009)

\begin{tabular}{|c|c|c|c|c|c|}
\hline \multicolumn{6}{|l|}{ Project stage } \\
\hline $\begin{array}{l}\text { Project level } \\
\text { status }\end{array}$ & Conceptual & Pre-feasibility & Feasibility & $\begin{array}{l}\text { Design and } \\
\text { construction }\end{array}$ & Operations \\
\hline $\begin{array}{l}\text { Geotechnical } \\
\text { level status }\end{array}$ & Level 1 & Level 2 & Level 3 & Level 4 & Level 5 \\
\hline $\begin{array}{l}\text { Geotechnical } \\
\text { characterisation }\end{array}$ & $\begin{array}{l}\text { Pertinent } \\
\text { regional } \\
\text { information }\end{array}$ & $\begin{array}{l}\text { Assessment and } \\
\text { compilation of } \\
\text { initial mine scale } \\
\text { geotechnical } \\
\text { data }\end{array}$ & $\begin{array}{l}\text { Ongoing } \\
\text { assessment and } \\
\text { compilation of all } \\
\text { new mine scale } \\
\text { geotechnical data }\end{array}$ & $\begin{array}{l}\text { Refinement of } \\
\text { geotechnical } \\
\text { database and } \\
\text { 3D model }\end{array}$ & $\begin{array}{l}\text { Ongoing } \\
\text { maintenance } \\
\text { of geotechnical } \\
\text { database and } \\
\text { 3D model }\end{array}$ \\
\hline \multicolumn{6}{|c|}{ Target levels of data confidence for each model } \\
\hline Geology & $>50 \%$ & $50-70 \%$ & $65-85 \%$ & $80-90 \%$ & $>90 \%$ \\
\hline Structural & $>20 \%$ & $40-50 \%$ & $45-70 \%$ & $60-75 \%$ & $>75 \%$ \\
\hline Hydrogeological & $>20 \%$ & $30-50 \%$ & $40-65 \%$ & $60-75 \%$ & $>75 \%$ \\
\hline Rock mass & $>30 \%$ & $40-65 \%$ & $60-75 \%$ & $70-80 \%$ & $>80 \%$ \\
\hline Geotechnical & $>30 \%$ & $40-60 \%$ & $50-75 \%$ & $65-85 \%$ & $>80 \%$ \\
\hline
\end{tabular}

\section{$5 \quad$ Impact of uncertainty on geomechanical design}

Uncertainty has a direct impact on the data confidence and reliability and thus has a direct impact on the design reliability. This would typically be due to increased Probability of Failure (PoF) for a given Factor of Safety (FoS), i.e. input data with a large spread or variability will result in a wider spread around the mean FoS and increase proportion of values with a FoS $<1$ (PoF). The higher the PoF the lower is the design reliability. Tapia et al. (2007) illustrate the relationship between FoS, PoF and level of uncertainty (Figure 1).

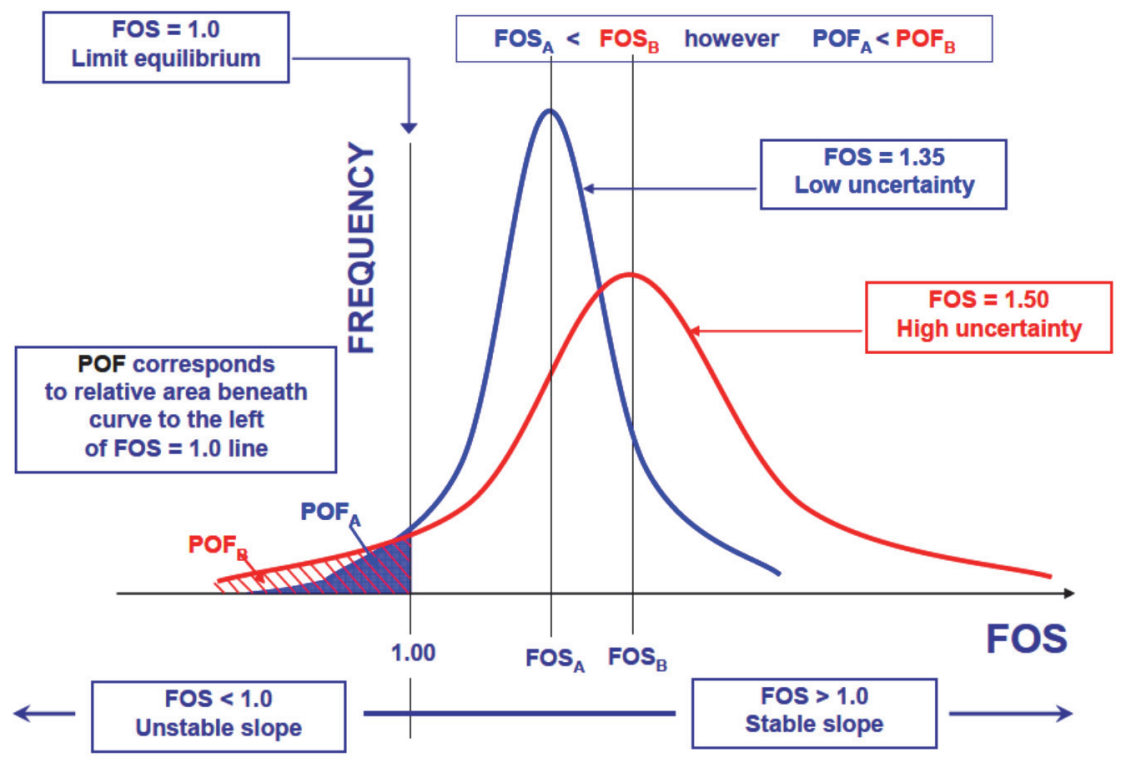

Figure 1 Definition of PoF and relationship with FoS and uncertainty magnitude (after Tapia et al. 2007) 
Silva et al. (2008) provide a good overview of probability of slope failure and have developed a semi-empirical relationship between FoS and annual PoF (Figure 2). This is based on their experience in the design of earthen structures and quantified expert judgement. The method of deriving the annual PoF is described in the paper and is not repeated here. Based on earlier work by Lambe (1985), relationships have been developed for four categories of design:

1. Category I: high failure consequences; facility designed, constructed and operated with a high level of engineering practice (best).

2. Category II: ordinary facilities designed, constructed and operated with standard engineering practices.

3. Category III: facilities without site specific design; temporary facilities with low failure consequences.

4. Category IV: facilities with little or no engineering (poor).

These categories relate to the level of engineering design input, including the underlying investigation and testing data and guidance is provided in terms of what is required. This can be related to geotechnical data and model requirements described by Read and Stacey (2009) and Cepuritis and Villaescusa (2012). Gover (2018) demonstrates how uncertainty affects both FoS and PoF and that minimisation of uncertainty reduces the PoF for a given FoS.

The relationship between annual PoF and FoS is shown in Figure 2. Mining projects or facilities probably fall in between Category II and Category III, although the annual PoF is seldom explicitly defined in mining geotechnical design. In mining geomechanical or geotechnical design, PoF is not routinely calculated and when it is, it is more likely to be the PoF over the lifetime of the facility which would be higher than the annual PoF shown in Figure 2.

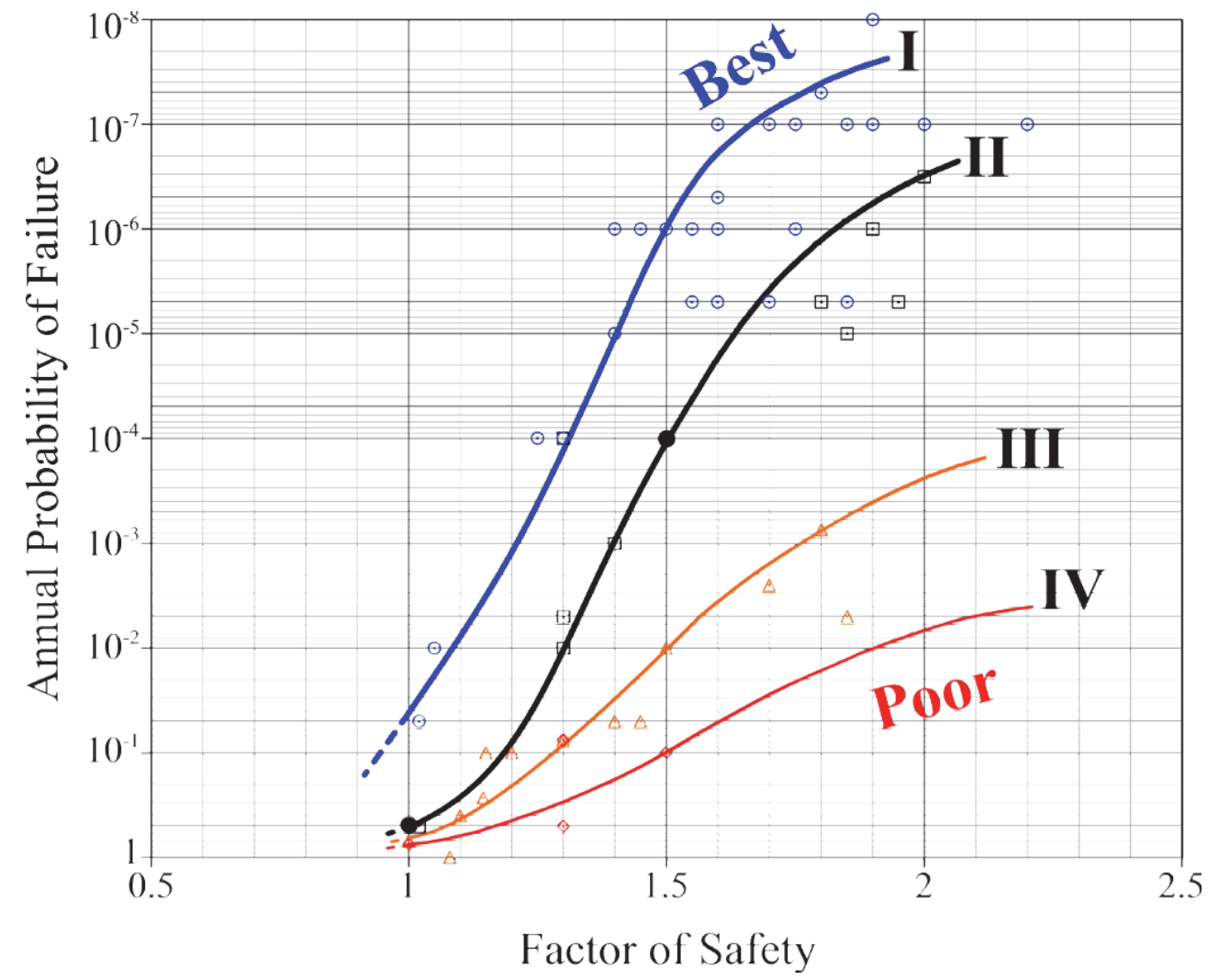

Figure 2 FoS versus annual PoF for 'best' engineering design practices (Category I) and 'poor' engineering design practice (Category IV) (after Silva et al. 2008) 
Jefferies et al. (2008) and Renani et al. (2018) discuss how choosing material inputs can influence the FoS and PoF of a slope. From this, it can be inferred that the use of mean values does not account adequately for the effect of the natural variability within a soil or rock mass. It is also generally known that materials rarely fail at their mean strength, thus it would be more suitable to use a lower value if a more reliable design is required. The issues associated with the selection of material properties for deterministic analyses can be overcome by using probabilistic analyses or at the very least undertaking a range of meaningful sensitivity analyses.

An outcome from probabilistic analyses is the PoF for a specific design and this is generally more meaningful than FoS and can be used in reliability-based design as well as risk assessments. It is also easier to compare designs using PoF. It could be argued that PoF is a way to measure and communicate the confidence of the underlying data and design analysis (Venter 2018). It is not always possible to undertake probabilistic analyses and deterministic analyses and FoS are more common, however, minimising, quantifying and understanding uncertainty in terms of inputs becomes even more important.

\section{$6 \quad$ Minimising uncertainty in geomechanical design}

The development of a reliable design requires the minimisation of uncertainty in the underlying data and the development of geotechnical models at the required confidence level and reliability. There are two aspects that need to be considered in mining geotechnical design. The first is the reduction in uncertainty of the geotechnical model and design as it progresses through the project lifecycle, and the second is the reduction in uncertainty related to the design from a safety or economic risk perspective.

The steps required to minimise uncertainty and reduce errors have previously been summarised by various authors (Dunn et al. 2011; Hadjigeorgiou \& Harrison 2011; Hadjigeorgiou 2012; Dunn 2013, 2015); this includes ensuring that:

- There is enough data with a good spatial distribution across the area of interest.

- Data bias is minimised or understood.

- Data quality is sufficient to make a reasonable or reliable estimate.

- The treatment and interpretation of the data is of a high quality.

- Ongoing review and improvement.

There are many aspects that need to be addressed within the areas outlined above. The minimisation of uncertainty in the geotechnical model and design requires that rigorous processes are in place for data collection, compilation, model development and engineering design. Once a geotechnical model has been developed, it is necessary to try and quantify the uncertainty associated with the model so that the confidence level and reliability can be estimated.

\section{$7 \quad$ Quantifying uncertainty}

Whilst minimisation of uncertainty is the primary goal, there is a practical limit to this endeavour which is related to natural variability of materials and the fact that it is virtually impossible to define, with absolute certainty, the position of all geological boundaries or the positions of structures. It is important to try and understand the spatial distribution of boundaries and develop some level of qualitative confidence in the spatial models. For parameter uncertainty, there are some tools that can be used to quantify the uncertainties and develop an understanding of natural variations that can be accounted for in the design process.

Ultimately, quantifying the uncertainty or qualitatively describing the various uncertainties is an important part of the geomechanical design process. It is important to understand how the uncertainty and reliability of the geomechanical or geotechnical model relates to the design hazards and risk assessment. It is also important to understand whether the risks are related to safety, economics, environmental or social; or if there is significant overlap. 
The amount of uncertainty and reduced design reliability that would be acceptable would be different for a non-entry stope versus the long-term mine access. In the case of the non-entry stope, excessive dilution and economic loss might be the issue whilst significant damage from a rockburst to a long-term access has the potential to injure people as well as result in loss of access to a mine, i.e. there are significant safety and economic risks. It would be a similar case for short life open pit slope, when compared to a long life open pit slope of significant height, with the potential to impact on critical surface infrastructure such as a crusher.

\subsection{Spatial model uncertainty}

The development of spatial models, which reflect the geological units, boundaries and major structures, is largely dependent on the density and spatial distribution of the data used to develop the model. There is a link to the data used for the resource model, but that is typically focused on the orebody and immediate surrounds. Therefore, the geological and structural model reliability tends to decrease away from the orebody.

The number of mapping points or drillhole intercepts, the location of these points, and the quality of the data collected at these points, all influence the interpretation. The implementation of quality control procedures is required to ensure that the survey is correct and that the data quality is satisfactory and will not compromise the interpretation and development of the model.

There is a range of sophisticated tools for the modelling of geology and structures, but the reliability of the model is largely dependent on the experience and judgement of the professional developing the model. For this reason, it is imperative that the models and input data be independently reviewed and verified.

Geotechnical block models are becoming more common place in the industry and these are largely dependent on the density and spatial distribution of the data used to develop models. In addition, there are several modelling parameters that can have a dramatic influence on the quality of the block model. Again, the reliability of the geotechnical block model is largely dependent on the experience and judgement of the professional developing the model and should also be subject to independent review and verification. Confirming the interpretation in the field on an ongoing basis is critical and will assist in increasing the block model reliability.

\subsection{Parameter uncertainty}

In the case of parameter models, there is generally some sort of measurement or description (e.g. rock mass characteristics, field testing, laboratory testing, orientation measurement, etc.) to which various statistical methods could be applied when assessing the reliability. The reliability of the data density and spatial distribution is largely dependent on the experience and judgement of the professional developing the model. This section will focus on some of the tools that can be used to assess the reliability of input parameters.

Fillion and Hadjigeorgiou (2013) explored how small sampling theory could be applied to assessing the results of laboratory testing from an operating mine, and this will not be repeated in this paper. They showed that even if the number of specimens tested is higher than the minimum proposed by the International Society for Rock Mechanics' suggested methods, the sample size was too small to obtain reliable strength values for most of the rock domains. It was also discovered that the minimum sample size obtained using the confidence interval approach is significantly influenced by the test results sequence used for the analyses. This can arise when samples from a relatively small zone are tested, resulting in misleading statistics. This highlights the need to have a reasonable spatial distribution of testing data so that the material variation is captured.

Read (2013) outlined two methods that could be used for assessing parameter uncertainty. The first is the coefficient of variation $\left(\mathrm{C}_{\mathrm{v}}\right)$ which is determined from the mean and standard deviation (SD) of a dataset and is expressed as a percentage. The $C_{v}$ is a measure of how variable a rock mass parameter is; typically, a $C_{v}$ value of less than $10 \%$ is considered low and values greater than $30 \%$ are considered high. Wiles (2006) 
demonstrated how the $C_{v}$ could be used in assessing the reliability of numerical modelling predictions. Gover (2018) demonstrated how materials with a lower $C_{v}$ resulted in a lower PoF for the same FoS.

Read (2013) concluded that whilst $C_{v}$ is a valuable screening mechanism when making decisions about the level of confidence in a selected design parameter, it is subjective and does not provide a numerical measure of the reliability of the data. It does provide an indication of how variable the rock mass is and can be used to compare the variability between different rock masses.

Read (2013) suggested a second approach to overcome this difficulty, based on a modified Bayesian approach (Harr 1996) to estimate the expected value of the reliability (E[R]) of a dataset. The method uses a simple spreadsheet format and can be applied to any set of geotechnical data. It is particularly useful for evaluating laboratory testing data. This method supplements the more common approach of using the mean, SD and median for assigning design input values. There would also be value in applying this approach to datasets for different study stages to assess whether the data reliability improves as the project progresses.

This approach has been applied by the author for different rock mass parameters for a range of mining projects (Dunn 2015; Mandisodza \& Dunn 2019) These data are not included in this paper but additional data from two other mining projects are included. Mine-1 includes Bieniawski (1989) rock mass rating (RMR ${ }_{89}$ ) data (Table 3) for pre-feasibility and feasibility studies, as well uniaxial compressive strength (UCS) testing data (Table 4). For Mine-2 UCS testing data is summarised (Table 5).

When applying this method to length-weighted data, the reliability is simply a function of the percentiles used, for example, the $25^{\text {th }}$ percentile $\left(P_{25}\right)$ would have an $E[R]$ of $75 \%$, i.e. $75 \%$ of the data exceeds the $P_{25}$ value. For point data or unweighted data, it is necessary to apply the method as described by Read (2013). For the $\mathrm{RMR}_{89}$ data, an increase in data from the pre-feasibility study to the feasibility study did not necessarily result in a reduced $C_{v}$ or an increased $E[R]$. It can be inferred that the $R_{M R} R_{89}$ statistics reflect the natural variability and that additional data does not reduce the uncertainty further.

It was also noted that a lower $C_{v}$ did not result in a higher $E[R]$ and this is consistent with results summarised in Dunn (2015) and Mandisodza and Dunn (2019). Generally, lower $C_{v}$ values were calculated for the RMR $R_{89}$ datasets than for the two UCS datasets.

Table 3 Mine-1 length-weighted $\mathrm{RMR}_{89}$ data descriptive statistics

\begin{tabular}{llllllllll}
\hline Rock unit & $\begin{array}{l}\text { Length } \\
(\mathbf{m})\end{array}$ & Mean & SD & $\begin{array}{l}\mathbf{C}_{\mathrm{v}} \\
(\%)\end{array}$ & $\mathbf{P}_{25}$ & $\mathbf{P}_{50}$ & $\mathbf{P}_{75}$ & $\begin{array}{l}\mathrm{E}[\mathrm{R}] \% \\
(\mathbf{m e a n})\end{array}$ & $\begin{array}{l}\mathrm{E}[\mathrm{R}] \% \\
\text { (mean - 0.5 } \times \text { SD) }\end{array}$ \\
\hline Rhyodacite (PFS) & 2,701 & 67 & 12 & 17 & 58 & 68 & 75 & 40 & 45 \\
Rhyodacite (FS) & 6,281 & 67 & 11 & 16 & 60 & 67 & 75 & 42 & 43 \\
Argillic (PFS) & 434 & 53 & 13 & 25 & 34 & 50 & 60 & 33 & 62 \\
Argillic (FS) & 3,900 & 51 & 14 & 28 & 40 & 52 & 62 & 31 & 53 \\
\hline
\end{tabular}

For the UCS testing data, it was observed that for both datasets an increased number of tests did not result in a reduction in $\mathrm{C}_{v}$. This is probably due to the presence of outliers and, in the cases of some rock types, the presence of different strength groupings within the sample, and that further analysis is required. This disparity demonstrates how $C_{v}$ can be used as a screening tool to better understand the data. However, if the UCS sample is representative of the population for a specific geotechnical domain, then additional testing is unlikely to change the $C_{v}$ and it reflects the natural variability in UCS for that rock mass. 
Table 4 Mine-1 UCS data descriptive statistics

\begin{tabular}{|c|c|c|c|c|c|c|c|c|c|}
\hline Rock unit & Count & $\begin{array}{l}\text { Mean } \\
\text { (MPa) }\end{array}$ & $\begin{array}{l}\text { SD } \\
\text { (MPa) }\end{array}$ & $\begin{array}{l}C_{v} \\
(\%)\end{array}$ & $\begin{array}{l}\mathrm{P}_{25} \\
(\mathrm{MPa})\end{array}$ & $\begin{array}{l}P_{50} \\
\text { (MPa) }\end{array}$ & $\begin{array}{l}\mathbf{P}_{75} \\
\text { (MPa) }\end{array}$ & $\begin{array}{l}E[R] \% \\
\text { (mean) }\end{array}$ & $\begin{array}{l}E[R] \% \\
(\text { mean - } 0.5 \times S D)\end{array}$ \\
\hline Mafic dykes & 5 & 83 & 13 & 40 & 29 & 30 & 35 & 43 & 71 \\
\hline Sediments & 8 & 55 & 20 & 37 & 39 & 55 & 66 & 50 & 60 \\
\hline Andesite & 8 & 27 & 22 & 81 & 9 & 22 & 36 & 50 & 60 \\
\hline Argillic & 57 & 35 & 27 & 79 & 16 & 31 & 50 & 47 & 55 \\
\hline Rhyodacite & 50 & 59 & 48 & 83 & 21 & 53 & 69 & 48 & 67 \\
\hline
\end{tabular}

It is possible to use the Students-T distribution to assess the confidence level of the datasets and for a selected design value. It was observed that in cases with a high $C_{v}$ value a very low value of the parameter would have to be selected to say satisfy a confidence level of $80 \%$. This is a further indicator that a more in-depth review of the UCS testing data is needed, especially for Mine-1.

Table 5 Mine-2 UCS data descriptive statistics

\begin{tabular}{|c|c|c|c|c|c|c|c|c|c|}
\hline Rock unit & Count & $\begin{array}{l}\text { Mean } \\
(\mathrm{MPa})\end{array}$ & $\begin{array}{l}\text { SD } \\
\text { (MPa) }\end{array}$ & $\begin{array}{l}C_{v} \\
(\%)\end{array}$ & $\begin{array}{l}P_{25} \\
(\mathrm{MPa})\end{array}$ & $\begin{array}{l}P_{50} \\
(\mathrm{MPa})\end{array}$ & $\begin{array}{l}P_{75} \\
(\mathrm{MPa})\end{array}$ & $\begin{array}{l}E[R] \% \\
\text { (mean) }\end{array}$ & $\begin{array}{l}E[R] \% \\
(\text { mean }-0.5 \times S D)\end{array}$ \\
\hline Andesite & 7 & 107 & 37 & 34 & 89 & 109 & 113 & 67 & 67 \\
\hline Upper volcaniclastic & 28 & 126 & 55 & 44 & 88 & 118 & 53 & 47 & 80 \\
\hline Lower volcaniclastic & 14 & 92 & 37 & 41 & 74 & 93 & 107 & 50 & 69 \\
\hline Lava & 15 & 129 & 36 & 28 & 109 & 130 & 156 & 50 & 71 \\
\hline Diorite & 34 & 110 & 75 & 68 & 40 & 97 & 188 & 47 & 61 \\
\hline Eastern volcaniclastic & 9 & 35 & 15 & 43 & 25 & 29 & 41 & 36 & 55 \\
\hline
\end{tabular}

\section{Conclusion}

The issues of geotechnical uncertainty and the impact on design analysis and PoF and FoS are discussed in this paper. The need to minimise uncertainty in the geomechanical or geotechnical model is outlined, however, it is important to accept that uncertainty cannot be completely eliminated. Therefore, it is necessary to understand the uncertainty so that it can be accounted for in the engineering design analysis and the risk assessment process.

Development of geotechnical models and inputs that have a confidence level and reliability commensurate with the desired design reliability and acceptable risk profile requires a rigorous process data collection, compilation, management and interpretation. Quantifying the confidence level or reliability of geotechnical models is challenging, especially with respect to spatial models such as the geology or structural model. There are tools available that can be used to assess parameter uncertainty and these have been applied to several datasets and show promise.

Based on the data summarised in this paper and in other papers (Dunn 2015; Mandisodza \& Dunn 2019) it is concluded that using mean input values for rock mass and intact strength parameters does not satisfy the confidence levels or reliability suggested by industry. Using a $P_{25}$ or mean- $0.5 \times$ SD provides inputs that are more in line with the target confidence levels defined by Read and Stacey (2009) and the reliability levels outlined by Cepuritis and Villaescasa (2012). Using lower inputs values more adequately reflects the effects of rock mass variability on the design. 
Ultimately, the level of uncertainty that can be accepted in a design will depend on the risk profile for the structure or facility that is deemed acceptable by the owner and society. For the geomechanical engineer, it is important that they consider and understand the uncertainty and attempt, where possible, to quantify the uncertainty and its potential impact on the design and risk profile. This needs to be effectively communicated to the decision makers and stakeholders so that informed decisions can be made.

\section{References}

Baecher, GB \& Christian, JT 2003, Reliability and Statistics in Geotechnical Engineering, John Wiley \& Sons, London.

Bieniawski, ZT 1989, Engineering Rock Mass Classifications, John Wiley \& Sons, New York.

Bieniawski, ZT 1992, 'Principles of engineering design for rock mechanics', in JR Tillerson \& WR Wawersik (eds), Proceedings of the 33rd US Symposium on Rock Mechanics, Taylor \& Francis, pp. 1031-1040.

Brown, ET 2007, Block Caving Geomechanics, Second Edition, Julius Kruttschnitt Mineral Research Centre, Indooroopilly, p. 696.

Cepuritis, P \& Villaescusa, E 2012, 'A reliability-based approach to open stope span design in underground mining', Proceedings of the 6th International Conference and Exhibition on Mass Mining, Canadian Institute of Mining, Metallurgy and Petroleum, Westmount.

Dunn, MJ 2013, 'Uncertainty in ground support design and implementation in underground mining', in Y Potvin \& B Brady (eds), Proceedings of the Seventh International Symposium on Ground Support in Mining and Underground Construction, Australian Centre for Geomechanics, Perth, pp. 345-358.

Dunn, MJ 2014, 'Geotechnical models and data confidence in mining geotechnical design', Proceedings of the Third Australasian Ground Control in Mining Conference, The Australasian Institute of Mining and Metallurgy, Melbourne, pp. 105-112.

Dunn, MJ 2015, 'How reliable are your design inputs?' in Y Potvin (ed.), Proceeding of the International Seminar on Design Methods in Underground Mining, Australian Centre for Geomechanics, Perth, pp. 367-381.

Dunn, MJ, Basson, FR \& Parrott, TT 2011, 'Geotechnical data - a strategic or tactical issue?', in Y Potvin (ed.), Proceedings of the Fourth International Seminar on Strategic versus Tactical Approaches in Mining, Australian Centre for Geomechanics, Perth, pp. 21-30.

Fillion, MH \& Hadjigeorgiou, J 2013, 'Reliability of strength estimates based on limited laboratory data', in P Dight (ed.), Proceedings of the 2013 International Symposium on Slope Stability in Open Pit Mining and Civil Engineering, Australian Centre for Geomechanics, Perth, pp. 163-176.

Gover, SM 2018, 'Linking safety factor to probability of failure', Proceedings Mine Waste and Tailings Stewardship Conference 2018 Conference Proceedings, The Australasian Institute of Mining and Metallurgy, Melbourne.

Hadjigeorgiou, J 2012, 'Where do the data come from?', in Y Potvin (ed.), Proceedings of the Sixth International Seminar on Deep and High Stress Mining, Australian Centre for Geomechanics, Perth, pp. 259-277.

Hadjigeorgiou, J \& Harrison, JP 2011, 'Uncertainty and sources of error in rock engineering', in Q Qian \& X Zhou (eds), Harmonising Rock Engineering and the Environment: Proceedings of the 12th ISRM International Congress on Rock Mechanics, CRC Press, Leiden, pp. 2063-2067.

Haile, A 2004, 'A reporting framework for geotechnical classification of mining projects', AusIMM Bulletin, September/October 2004, Melbourne, pp. 30-37.

Haines, A, Swart, A \& Kruger, A 2006, 'Proactively mitigating geotechnical risks in open pit and underground mining', in Y Potvin (ed.), Proceedings of the Second International Seminar on Strategic versus Tactical Approaches in Mining, Australian Centre for Geomechanics, Perth.

Harr, ME 1996, Reliability-Based Design in Civil Engineering, McGraw-Hill, Dover.

Jefferies, M, Lorig L \& Alvarez, C 2008, 'Influence of rock strength spatial variability on slope stability', in R Hart, C Detournay \& P Cundall (eds), Proceedings First International FLAC/DEM Symposium on Numerical Modelling, Itasca, Minneapolis.

Joint Ore Reserves Committee 2004, JORC Code: Australasian Code for Reporting of Exploration Results, Mineral Resources and Ore Reserves, Joint Ore Reserves Committee, Carlton South.

Joint Ore Reserves Committee 2012, JORC Code: Australasian Code for Reporting of Exploration Results, Mineral Resources and Ore Reserves, Joint Ore Reserves Committee, Carlton South.

Lambe, TW 1985, 'Amuay landslides', Proceedings of 11th International Conference on Soil Mechanics and Foundation Engineering, Golden Jubilee Volume, A.A. Balkema, Rotterdamn, pp. 137-158.

Mandisodza, KT \& Dunn, MJ 2019, 'Geotechnical design and uncertainty in residual soil slopes', in J Wesseloo (ed.), Proceedings of the First International Conference on Mining Geomechanical Risk, Australian Centre for Geomechanics, Perth, pp. 475-492.

McMahon, BK 1985, 'Geotechnical design in the face of uncertainty: EH Davis memorial lecture', Australian Geomechanics Journal, issue 10, pp. 7-19, Australian Geomechanics Society, Barton.

Peck, RB 1969, 'Advantages and limitations of the observational method in applied soil mechanics', Géotechnique, vol. 19, no. 2, pp. 171-187.

Read, J 2013, 'Data gathering, interpretation, reliability and geotechnical models', in P Dight (ed.), Proceedings of the 2013 International Symposium on Slope Stability in Open Pit Mining and Civil Engineering, Australian Centre for Geomechanics, Perth, pp. 81-89.

Read, J 2009, 'Data uncertainy', in J Read \& P Stacey (eds), Guidelines for Open Pit Slope Design, CSIRO Publishing, Collingwood, pp. 213-220. 
Renani, HR, Martin, CD, Varona, P \& Lorig, L 2018, 'Probabilistic stability analysis of slopes in highly heterogeneous rock masses', Proceedings of Slope Stability Symposium 2018, BCO Congresos, Barcelona.

Silva, FM, Lambe, TW \& Marr, WA 2008, 'Probability and Risk of Slope Failure', Journal of Geotechnical and Geoenvironmental Engineering, vol. 134, no. 12.

Stacey, TR 2004, 'The link between the design process in rock engineering and the code of practice to combat rock fall and rockburst accidents', The Journal of The South African Institute of Mining and Metallurgy, pp. 29-34.

Stacey, TR 2008, 'Are design codes appropriate in mining rock engineering?', in Y Potvin, J Carter, A Dyskin \& R Jeffrey (eds), Proceedings of the 1st Southern Hemisphere International Rock Mechanics Symposium, Volume One - Mining and Civil, Australian Centre for Geomechanics, Perth, pp. 129-136.

Stacey, TR 2009, 'Design-a strategic issue', The Journal of The Southern African Institute of Mining and Metallurgy, vol. 109, pp. 157-162.

Steffen, OKH 1997, 'Planning of open pit mines on risk basis', The Journal of The South African Institute of Mining and Metallurgy, vol. 2, pp. 47-56.

Tapia, A, Contreras, LF, Jefferies, M, \& Steffen, O 2007, 'Risk evaluation of slope failure at the Chuquicamata mine', in Y Potvin (ed.), Proceedings of the 2007 International Symposium on Rock Slope Stability in Open Pit Mining and Civil Engineering, Australian Centre for Geomechanics, Perth, pp. 477-495.

Venter, J 2018, 'Slope design - from A to Z', Geotechnical Engineering for Open Pit Open Mines Course, Australian Centre for Geomechanics, Perth.

Villaescusa, E 2014, Geotechnical Design for Sublevel Open Stoping, CRC Press, Boca Raton, p. 541.

Vyazmensky, A 2017, Geotechnical or Geomechanical?, Minex Forum, http://minexforum.com/en/geotechnical-or-geomechanical/

Wiles, TD 2006, 'Reliability of numerical modelling predictions', International Journal of Rock Mechanics and Mining Sciences, vol. 43, pp. 454-472. 
